\title{
... und alles wegen zehn Euro
}

\section{Von AOKen und Advokaten, von KVen und Kriegsopfern}

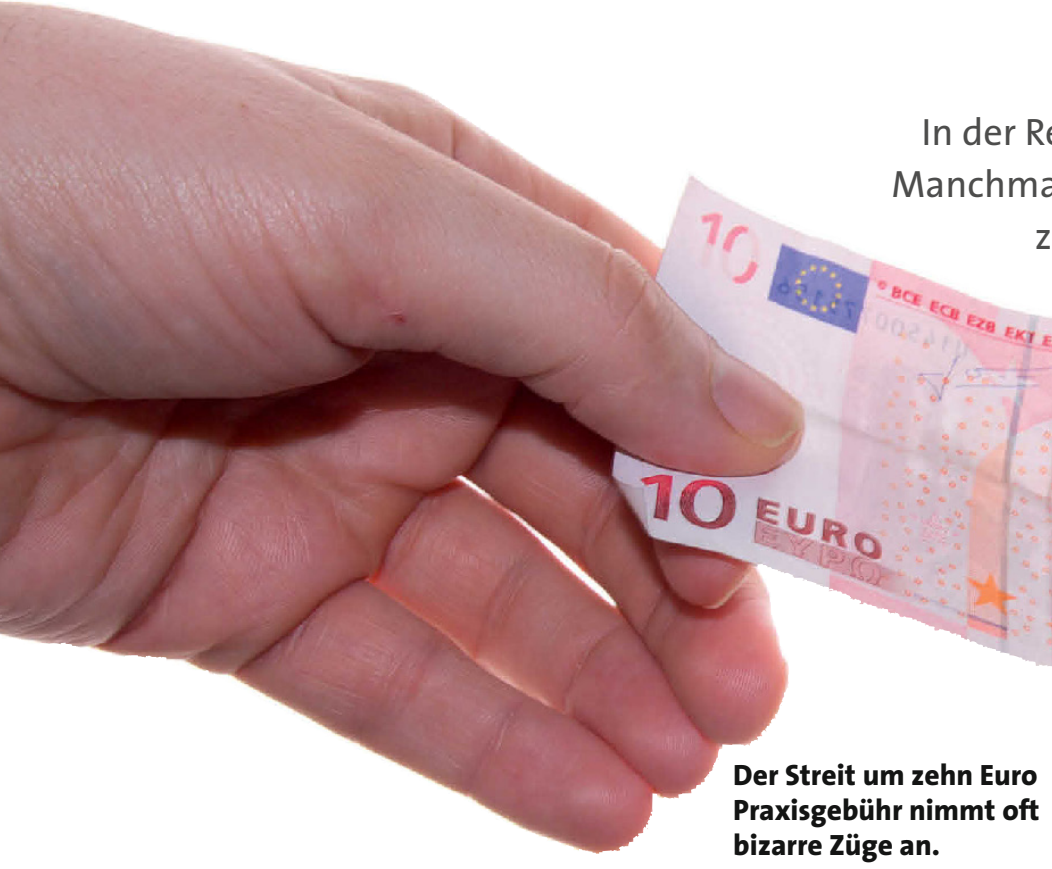

Der Streit um zehn Euro bizarre Züge an. zu gebrauchen - zur Sprache gebracht werden. Meist

geht es dann um die Kassen und die KV, wie hier

bei der Zehn-Euro-Praxisgebühr. $\sqrt{ }$ ermutlich kennen Sie die immer kleiner werdende Gruppe derer, die als „Kriegsopfer“ einen Sonderstatus bei den RVO-Kassen haben. Deren Befreiung von Zuzahlungen, auch von den oben genannten zehn Euro, ist auf ihrer Versichertenkarte mit dem Status 10006 dokumentiert. Ihre Chipkarte sieht wie eine AOK-Karte aus und in der Tat erfolgt die Verwaltung auch über die AOK Aschaffenburg.

Nun kommt es hin und wieder vor, dass die Praxishelferin eines Notdienstes beim Einlesen der Chipkarte diesen vom Praxiscomputer im Klartext angezeigten „exotischen“ Status nicht kennt und unterdrückt. Daraufhin erhält der Patient eine Mahnung, die nach einem Anruf in der Praxis geklärt scheint - so meint man jedenfalls.

Was nun folgt ist eine Posse, die das Kassen- und KV-Leben schreibt: Als nächstes kommt ein schon etwas rüderer Brief von einer Anwaltskanzlei. Diese hat die KV sinnvollerweise im Schwabenland installiert, wo angeblich die Schotten Deutschlands leben. Ruft man dort an, landet man in einem ZehnPunkte-Menü, das schon bei jüngeren Anrufern ein gewisses Gehirnjogging voraussetzt. Nach entsprechender Wartezeit hat man mit etwas Glück jemanden an der Strippe, der höchst unfreundlich mitteilt, die Beweislast liege ja nun beim Angeschriebenen respektive dem Angemahnten. Also: die zehn Euro zahlen oder eine Befreiungs-Bescheinigung vorlegen! Bei dem Versuch weiterer Erklärungen wird der Hörer aufgelegt. Doch Pech gehabt: Die AOK Aschaffenburg schickt ein freundliches Schreiben, dass sie den angeforderten Befreiungsbescheid nicht erstellen könne, da der Status ja aus der Chipkarte hervorgehe. Diese wiederum wurde - da vom Vorjahr - bereits wunschgemäß vernichtet. Ein Anruf bei der zuständigen örtlichen KV, die ja die über die Abrechnung eingelesenen Patientendaten kennen müsste, ergibt, dass sie dafür nicht mehr zuständig sei, sondern alles vorschriftsgemäß an die oben genannte Kanzlei abgegeben worden sei. Da gebe es zwar immer Beschwerden, angeordnet sei das aber von „ganz oben - aus Berlin“. Die KV verfügt, wie wir von unseren Abrechnungen zur Genüge wissen, über jede Menge Daten und müsste auch jene der Chipkarten haben. Merkwürdig also, dass die KV diesen Circulus vitiosus nicht schon anfänglich unterbindet, sondern eine Kanzlei tätig werden lässt. Bei dieser wiederum hatte man das ungute Gefühl: Je sperriger sich deren Mitarbeiter stellen, umso mehr verdienen sie an dem Fall und es drängt sich der Verdacht auf, dass hier eine Gruppe von Rechtsanwälten auf eine Goldader gestoßen ist. Bleibt die Frage: Wer finanziert diese Kanzlei? Das Bundesgesundheitsministerium über den Steuerzahler? Die Kassen über ihre Mitgliedsbeiträge? Oder wieder einmal wir dummen Ärzte über unsere KV-Abgaben?

Die einzigen, die sich in diesem Trauerspiel um eine (letztlich erfolgreiche?) Lösung bemühten und mit der Kanzlei auseinandersetzten, waren die stets freundlichen und hilfsbereiten Mitarbeiter/innen der AOK Aschaffenburg. Dort gab es tatsächlich so etwas wie eine Kultur im Umgang mit dem Kunden, der ja in der Regel ein Patient (zu deutsch: Leidender) ist - wovon alle anderen beteiligten Stellen weit entfernt waren. 